\title{
Secretory Leukocyte Protease Inhibitor Suppresses the Production of Monocyte Prostaglandin H Synthase-2, Prostaglandin $\mathrm{E}_{2}$, and Matrix Metalloproteinases
}

\author{
Yahong Zhang, ${ }^{\star}$ David L. DeWitt, ${ }^{\ddagger}$ Tessie B. McNeely, ${ }^{\star}$ Sharon M. Wahl, ${ }^{\star}$ and Larry M. Wahl ${ }^{\star}$ \\ *Cellular Immunology Section, Laboratory of Immunology, National Institute of Dental Research, Bethesda, Maryland 20892-4352; and \\ ${ }^{\ddagger}$ Michigan State University, Department of Biochemistry, East Lansing, Michigan 48824
}

\begin{abstract}
Secretory leukocyte protease inhibitor (SLPI) is a serine protease inhibitor found in fluids lining mucosal surfaces. In addition to its primary function as an antiprotease, SLPI may also influence cellular functions associated with enzyme synthesis and retroviral infection. In this study, SLPI was examined for its effect on signaling events involved in the production of matrix metalloproteinases (MMPs) by monocytes. Addition of SLPI before stimulation with concanavalin A or LPS resulted in a significant inhibition of monocyte prostaglandin $\mathrm{H}$ synthase-2 (PGHS-2), a pivotal enzyme in the $\mathrm{PGE}_{2}$-cAMP dependent pathway of monocyte MMP synthesis. Suppression of PGHS-2 was detected with $0.1 \mu \mathrm{g} / \mathrm{ml}$ of SLPI with a substantial inhibition at 1 and $10 \mu \mathrm{g} / \mathrm{ml}$. Attenuation of PGHS-2 by SLPI was accompanied by decreased production of $\mathrm{PGE}_{2}$ resulting in the suppression of interstitial collagenase (MMP-1) and gelatinase $\mathrm{B}$ (MMP-9) that was reversed by $\mathrm{PGE}_{2}$ or $\mathrm{Bt}_{2} \mathrm{cAMP}$. The inhibitory effect of SLPI was largely independent of its antiprotease activity because SLPI muteins, with significantly lower antiprotease activity, also suppressed the induction of PGHS-2 and MMPs. The inhibitory effects of SLPI did not involve the modulation of monokine production since TNF- $\alpha$ and IL-10 were unaffected. These findings demonstrate that SLPI also functions as a potent antiinflammatory agent by interfering with the signal transduction pathway leading to monocyte MMP production. (J. Clin. Invest. 1997. 99:894900.) Key words: inflammation - connective tissue • collagenase $\bullet$ cyclooxygenase $\bullet$ signal transduction
\end{abstract}

\section{Introduction}

Secretory leukocyte protease inhibitor (SLPI) ${ }^{1}$ is a serine protease inhibitor found in large quantities in bronchial, nasal, and cervical mucous, saliva, and seminal fluid $(1,2)$. This $12-\mathrm{kD}$ protein is comprised of two homologous cysteine-rich domains of 53 and 54 amino acids and has inhibitory activity against chymotrypsin, trypsin, neutrophil elastase, and cathep$\sin \mathrm{G}(3,4)$. The protease-inhibitory site of SLPI resides at leu-

Address correspondence to Larry M. Wahl, Laboratory of Immunology, NIDR, NIH, 30 Convent Drive, MSC 4352, Bethesda, MD 20892-4352. Phone: 301-496-9219; FAX: 301-402-1064.

Received for publication 24 April 1996 and accepted in revised form 9 December 1996.

1. Abbreviations used in this paper: $\mathrm{Bt}_{2} \mathrm{CAMP}$, dibutyryl cAMP; $\mathrm{Con} \mathrm{A}$, concanavalin A; MMPs, matrix metalloproteinases; MMP-1, interstitial collagenase; MMP-9, gelatinase B; PGHS, prostaglandin H synthase; SLPI, secretory leukocyte protease inhibitor.

The Journal of Clinical Investigation

Volume 99, Number 5, March 1997, 894-900 cine 72 in the $\mathrm{COOH}$-terminal domain (5). The antiprotease properties of SLPI appear to serve as an important protective component of secretory fluids at sites of degenerative and inflammatory diseases. In addition to its ability to inhibit proteases, SLPI has recently been shown to inhibit HIV-1 replication in cultured human monocytes (6). This latter observation suggested that other functions of the monocyte may be regulated by SLPI.

One of the functions ascribed to activated monocytes/macrophages is the ability to produce matrix metalloproteinases (MMPs). MMPs are a family of extracellular matrix degrading enzymes comprised of the interstitial collagenases, type IV basement membrane collagenases or gelatinases, stromelysins, matrilysin, elastase, and membrane-type matrix MMPs (7). The interstitial collagenases specifically cleave the fibrillar collagens while the other enzyme members are capable of degrading proteoglycans, fibronectin, laminin, other collagens, gelatin, and elastin. Thus, collectively, the MMP family can degrade all of the extracellular matrix components.

Production of interstitial collagenase (MMP-1), 92-kD type IV basement membrane collagenase/gelatinase B (MMP-9) or matrilysin (MMP-7) by activated monocytes/macrophages has been shown to occur through a prostaglandin $\mathrm{E}_{2}$-cAMP dependent pathway (8-15). Signaling through this pathway involves the modulation of prostaglandin $\mathrm{H}$ synthase/cyclooxygenase (EC 1.14.99.1, PGHS, COX) (13). Two prostaglandin synthase isoforms have been identified, referred to as PGHS-1 and PGHS-2, and are found in many cell types (see review reference 16). PGHS-1 is a constitutively expressed enzyme involved in maintaining low levels of prostaglandins that are thought to be involved in housekeeping functions such as vascular homeostasis. In contrast, PGHS-2, while generally absent in cells, is induced in response to cell activators such as growth factors, cytokines, and phorbol esters, suggesting that this enzyme is involved in the generation of prostaglandins in inflammation. Similarly, monocytes have constitutive levels of PGHS-1 and only express PGHS-2 when activated by agents such as LPS, concanavalin A (Con A) or PMA (13, 14, 17-19). The induction of PGHS-2 in monocytes and the resulting production of $\mathrm{PGE}_{2}$ has been shown to be involved in the signal transduction pathway leading to MMP production by these cells (14).

The association of monocytes with chronic inflammatory diseases suggests that these cells may be intimately involved in the destruction of connective tissue in these lesions. Thus, the delineation of potential agents that may regulate the induction of MMPs is critical to the formulation of strategies to control the excessive production of MMPs. The possibility that the naturally occurring molecule SLPI might be one of these agents led us to determine whether it would modulate the signal transduction pathway leading to the production of MMPs by monocytes. Here we report that SLPI inhibits MMP production by human monocytes due to the reduction in $\mathrm{PGE}_{2}$ 
synthesis as a result of suppression of the induction of PGHS-2. This effect appears to be primarily independent of the protease inhibitory properties of SLPI.

\section{Methods}

Purification of human monocytes by counterflow centrifugal elutriation. Human peripheral blood cells were obtained by leukapheresis of normal volunteers at the Department of Transfusion Medicine at the National Institutes of Health (Bethesda, MD). These cells were diluted in endotoxin-free PBS without $\mathrm{Ca}^{2+}$ and $\mathrm{Mg}^{2+}$ (BioWhittaker, Walkersville, MD) and layered over $20 \mathrm{ml}$ of endotoxin-free lymphocyte sedimentation medium (LSM; Organon Teknika Corp., Durham, NC) in 50-ml tubes (Falcon, Division of Becton-Dickinson and Co., Oxnard, CA). After density sedimentation at $400 \mathrm{~g}$ for $30 \mathrm{~min}$, the monocytes in the mononuclear cell layer were purified by counterflow centrifugal elutriation (CCE) on a Beckman elutriation system as previously described $(20,21)$, except that pyrogen-free phosphatebuffered saline was used in the elutriation procedure. Monocytes were enriched to $>90 \%$ as determined by morphology, nonspecific esterase staining, and flow cytometry. Moreover, the purification procedure did not activate the monocytes as shown by the fact that after overnight incubation at $37^{\circ} \mathrm{C}$ in suspension $<4 \%$ of these cells were IL-2 receptor positive, a sensitive marker of monocyte activation (22).

Culture conditions. Purified monocytes were cultured in Dulbecco's Modified Eagles Medium (DME; BioWhittaker, Walkersville, $\mathrm{MD}$ ) supplemented with $2 \mathrm{mM}$ L-glutamine (Mediatech, Washington, DC) and $10 \mu \mathrm{g} / \mathrm{ml}$ gentamicin sulfate (BioWhittaker). Control or Con A (Burroughs Wellcome Co., Research Triangle Park, NC) or LPS (Escherichia coli O55:B5, Difco, Detroit, MI) stimulated monocytes were cultured in the presence or absence of recombinant SLPI or SLPI muteins, prepared by site-directed mutagenesis in which leucine 72 in the COOH-terminal domain, the inhibitory site for elastase, chymotrypsin, and trypsin, was replaced by glycine, phenylalanine, arginine, lysine, or valine (Amgen, Boulder, CO). Because SLPI or the muteins are partially degraded by repeated freeze thawing or if stored at $4^{\circ} \mathrm{C}$, frozen aliquots of these reagents were thawed immediately before use in each experiment. Dibutyryl cAMP ( $\left.\mathrm{Bt}_{2} \mathrm{cAMP}\right)$ and $\mathrm{PGE}_{2}$ (Sigma Chemical Co., St. Louis, $\mathrm{MO}$ ) were also added to some of the cultures. In some experiments serine protease inhibitors other than SLPI were added to monocyte cultures. These included: AEBSF [4-(2-aminoethyl)-benzenesulfonylfluoride hydrochloride] (Calbiochem, La Jolla, CA); soybean trypsin inhibitor (STI) (Sigma Chemical Co.); or $\alpha$-PI ( $\alpha$-protease inhibitor; an elastase inhibitor). The results are representative of observations obtained in three or more experiments using cells from different donors.

Extraction of RNA and Northern blot analysis. Total cellular RNA was extracted from nonadherent control or stimulated monocytes with guanidine thiocyanate as previously described (23). Cultures for mRNA analysis were harvested $18 \mathrm{~h}$ after LPS or Con A stimulation. The RNA samples $(5 \mu \mathrm{g})$ were subjected to formaldehyde-agarose gel electrophoresis and transferred in $10 \times$ SSC $(1 \times$ SSC is $0.15 \mathrm{M}$ $\mathrm{NaCl}, 0.015 \mathrm{M}$ sodium citrate) to nitrocellulose membranes (Schleicher \& Schuell, Inc., Keene, NH). After baking at $80^{\circ} \mathrm{C}$ for $2 \mathrm{~h}$, the membranes were prehybridized for $4 \mathrm{~h}$ at $42^{\circ} \mathrm{C}$ followed by overnight hybridization in $50 \%$ formamide, $10 \%$ dextran sulfate, $5 \times$ SSC, $5 \times$ Denhardt's solution $(0.1 \%$ bovine serum albumin, $0.1 \%$ polyvinylpyrrolidone and $0.1 \%$ Ficoll 400 ), $0.05 \mathrm{M}$ Na phosphate, $0.1 \%$ SDS, $0.005 \mathrm{M}$ EDTA, $50 \mu \mathrm{g} / \mathrm{ml}$ denatured salmon sperm DNA, and $100 \mu \mathrm{g} / \mathrm{ml}$ denatured yeast tRNA. High specific activity ${ }^{32} \mathrm{P}$-labeled DNA probes $\left(>10^{9} \mathrm{cpm} / \mu \mathrm{g}\right)$ were generated by the use of the Random Primers labeling system (Gibco BRL, Bethesda, MD) and were added at $5 \times 10^{6} \mathrm{cpm} / \mathrm{ml}$ hybridization solution. The cDNA probes used were the 1156-bp EcoRI fragment of mouse PGHS-2 (24), and the 2054-bp PstI fragment of human fibroblast interstitial collagenase (25). All the membranes were reprobed with human GAPDH (glyc- eraldehyde-3-phosphate dehydrogenase) cDNA (Gibco BRL) to verify that equal amounts of RNA were loaded per lane. The hybridized filters were washed twice in $2 \times$ SSC, $0.1 \%$ SDS at room temperature for $15 \mathrm{~min}$ each, followed by a high stringency wash, $0.1 \times \mathrm{SSC}, 0.1 \%$ SDS at $55^{\circ} \mathrm{C}$ for $30 \mathrm{~min}$ and placed onto phosphorimager screens for 24 h (Molecular Dynamics, Sunnyvale, CA). Scanned images were produced from phosphorimages using the Macintosh version of Adobe Photoshop (Adobe Systems Inc., Mountain View, CA) and a Microtek MSF-300ZS Flatbed Image Scanner (Microtek International, Inc., Hsinchu, Taiwan). Images were printed by a Phaser CP Color Printer (Tektronix, Inc., Beaverton, OR).

Cell protein isolation. Purified human monocytes, $20 \times 10^{6}$ cells in $4 \mathrm{ml}$ of DME, were cultured in suspension at $37^{\circ} \mathrm{C}$ in $17 \times 100 \mathrm{~mm}$ polypropylene tubes (Falcon 2059; Falcon Labware, Oxnard, CA) for $18 \mathrm{~h}$ under various experimental conditions. The cells were then washed in PBS with protease inhibitors $(2 \mu \mathrm{g} / \mathrm{ml}$ aprotinin, $2 \mu \mathrm{g} / \mathrm{ml}$ leupeptin, $10 \mu \mathrm{g} / \mathrm{ml}$ soybean trypsin inhibitor, and $100 \mu \mathrm{g} / \mathrm{ml}$ AEBSF (4-[2-aminoethyl]-benzenesulfonylfluoride-HCl) (Calbiochem, La Jolla, $\mathrm{CA}$ ). The pellets were suspended in $250 \mathrm{mM}$ sucrose containing protease inhibitors and sonicated (Ultrasonic Cell Disrupter; Kontes, Vineland, NJ). The nuclear debris and unbroken cells were pelleted at $100 \mathrm{~g}$ for $15 \mathrm{~min}$ in a refrigerated microfuge. The supernatant was microfuged at $1,500 \mathrm{~g}$ for $30 \mathrm{~min}$ to pellet cell membrane proteins. The protein concentration of the pellet was then determined by the Bradford assay (Bio-Rad, Melville, NY). Equal amounts of protein were utilized for all procedures as described in the figure legends.

$P G E_{2}$ assay. $\mathrm{PGE}_{2}$ levels in the media supernatants from monocyte cultures were determined by RIA as described (26) using rabbit anti-PGE ${ }_{2}$ antiserum (Upstate Biotechnology, Inc., Lake Placid, $\mathrm{NY}$ ). In general, $\mathrm{PGE}_{2}$ levels were measured $24 \mathrm{~h}$ after stimulation to allow for maximal accumulation of this prostaglandin in the media.

Cytokine assays. The levels of TNF- $\alpha$, IL-10, and IL-6 in the supernatants from monocyte cultures $\left(2 \times 10^{6} / 0.5 \mathrm{ml}\right.$ of DME/well of a 24-well plate) were determined by ELISA (Endogen, Cambridge, MA) according to the instructions of the manufacturer.

Western analysis. For determination of MMPs, proteins in the conditioned media from monocyte cultures were precipitated $48 \mathrm{~h}$ after LPS or Con A stimulation (the time of maximal MMP production) with cold ethanol (final concentration $60 \%$ ) at $-70^{\circ} \mathrm{C}$ for at least $30 \mathrm{~min}$. Pelleted proteins $(12,000 \mathrm{~g}$ for $20 \mathrm{~min}$ ) were washed with $1 \mathrm{ml}$ of ethanol and subsequently lyophilized (rotary evaporator). For PGHS-2 analysis, $100 \mu \mathrm{g}$ of cell protein, isolated as described above from cells harvested $18 \mathrm{~h}$ after stimulation, were dried by rotary evaporation. The lyophilized proteins were resuspended in SDS-Laemmli loading buffer (500 mM Tris- $\mathrm{HCl}[\mathrm{pH} \quad 6.8] / 10 \%$ SDS $/ 0.01 \%$ bromophenol-blue $/ 20 \%$ glycerol), reduced with $1 \% \beta$-mercaptoethanol, heated for $2 \mathrm{~min}$ at $95^{\circ} \mathrm{C}$, loaded and electrophoresed on a discontinuous $8 \%$ (PGHS-2) or a $8-16 \%$ (MMP) Tris-glycine gradient polyacrylamide gel (Novex, San Diego, CA) in SDS running buffer ( $25 \mathrm{mM}$ Tris-HCl [pH 8.3]/192 mM glycine/10\% SDS). After electrophoresis, the proteins from membranes or conditioned supernatants were transferred onto $0.45 \mu \mathrm{m}$ nitrocellulose in a buffer containing $25 \mathrm{mM}$ Tris- $\mathrm{HCl}(\mathrm{pH} 8.3) / 192 \mathrm{mM}$ glycine/20\% methanol and blocked with $50 \mathrm{mM}$ Tris- $\mathrm{HCl}(\mathrm{pH} 7.5) / 150 \mathrm{mM} \mathrm{NaCl} / 0.3 \%$ Tween-20 (TBST) containing $5 \%$ nonfat dry milk for at least $1 \mathrm{~h}$. The blots were washed three times with TBST and then incubated for $1 \mathrm{~h}$ or overnight with primary antibody. For the detection of MMPs, the blots were incubated with peptide specific MMP antibodies followed by protein A-horseradish peroxidase (1:3,000 dilution in TBST containing 5\% nonfat dry milk; Amersham Corp., Arlington Heights, IL) and developed with the enhanced chemiluminescence (ECL) detection system (Amersham Corp.). Affinity purified antibody against the inducible form of prostaglandin synthase (PGHS-2) was generated against a unique $\mathrm{COOH}$-terminal sequence (CYSHSRLDDINPTVLIK), which is not found in the PGHS-1 protein (27). In some experiments an affinity purified antibody against PGHS-1 was used to determine if the changes in PGHS-2 were also reflected in PGHS-1. 


\section{Results}

Inhibition of prostaglandin H synthase-2 in monocytes by SLPI. Since the production of MMPs by monocytes is regulated through a $\mathrm{PGE}_{2}$-dependent pathway involving the induction of PGHS-2, we initially examined the effect of SLPI on PGHS-2. Monocytes were stimulated with either Con A or LPS in the presence or absence of SLPI and examined for PGHS-2 mRNA and protein. As shown in Fig. 1, LPS or Con A induced the expression of PGHS-2 mRNA (Fig. $1 A$ ) or protein (Fig. $1 B$ ), which was absent in control monocytes. When monocytes were incubated with SLPI for $30 \mathrm{~min}$ before stimulation there was a dose-dependent inhibition of PGHS-2. This suppression was detected with as little as $0.01-0.1 \mu \mathrm{g} / \mathrm{ml}$ of SLPI. At higher doses ( 1 or $10 \mu \mathrm{g} / \mathrm{ml}$ ), SLPI caused a significant reduction in inducible PGHS-2. In contrast to PGHS-2, the endogenous isoform of cyclooxygenase, PGHS-1, was unaffected by SLPI (data not shown). As shown in Fig. 2, addition of SLPI $1 \mathrm{~h}$ before LPS caused a significant inhibition of PGHS-2 with a lesser but still pronounced inhibition if SLPI was added $30 \mathrm{~min}$ before LPS. Even if SLPI was added at the same time as LPS some inhibition was observed; however this inhibitory effect was almost completely lost if SLPI was added 30 min after LPS. These results demonstrate that SLPI acts early in the signaling pathway, and it is a potent inhibitor of PGHS-2 at concentrations that are well within the physiological range (1-10 $\mu \mathrm{g} / \mathrm{ml})$ found, for example, in saliva (6). Moreover, SLPI suppressed the induction of PGHS-2 by either Con A or LPS, two activators that have different receptors, suggest-

A

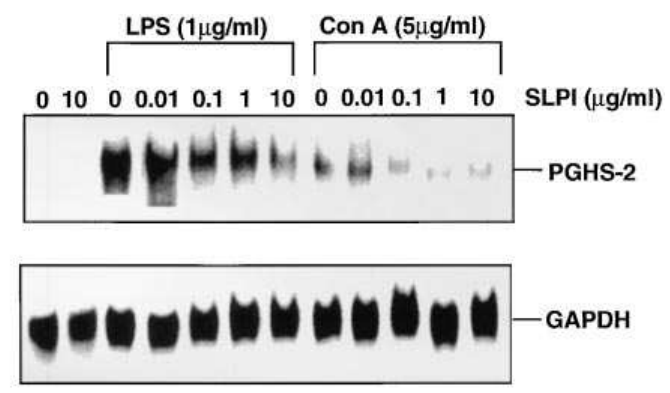

B

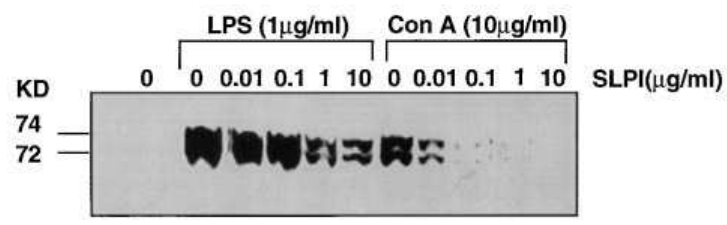

Figure 1. Effect of SLPI on the induction of PGHS-2 in monocytes. (A) Purified human peripheral blood monocytes, $20 \times 10^{6} / 4 \mathrm{ml}$ of DME, were cultured in suspension in the presence or absence of SLPI at the indicated concentrations for $30 \mathrm{~min}$, and then LPS $(1 \mu \mathrm{g} / \mathrm{ml})$ or Con A $(5 \mu \mathrm{g} / \mathrm{ml})$ were added to some of the cultures. Total RNA was isolated $18 \mathrm{~h}$ after the addition of LPS or Con A. RNA $(5 \mu \mathrm{g})$ from each sample was subjected to Northern blot analysis with the indicated probes. (B) Purified monocytes, $20 \times 10^{6} / 4 \mathrm{ml}$ of DME, were incubated in suspension for $30 \mathrm{~min}$ with SLPI at the indicated concentrations and then LPS or Con A was added to some of the cultures. The cultures were harvested $18 \mathrm{~h}$ after stimulation with LPS or Con A and equal amounts of membrane protein $(100 \mu \mathrm{g})$ were separated on $8 \%$ discontinuous Tris-glycine gels and subjected to Western blot analysis using affinity purified PGHS-2 antisera.

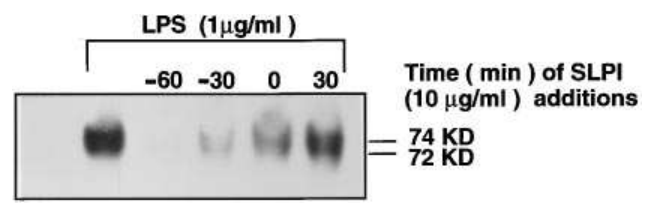

Figure 2. Effect of time of addition of SLPI on the induction of PGHS- 2 in monocytes. SLPI was added to purified monocytes, $20 \times$ $10^{6} / 4 \mathrm{ml}$ of DME, at the indicated times relative to the addition of LPS. The cultures were harvested $18 \mathrm{~h}$ after stimulation with LPS and equal amounts of membrane protein $(100 \mu \mathrm{g})$ were separated on $8 \%$ discontinuous Tris-glycine gels and subjected to Western blot analysis using affinity purified PGHS-2 antisera.

ing that the mechanism of activation did not involve downregulation of a specific receptor.

$S L P I$ inhibits monocyte prostaglandin $E_{2}$ production. The effect of SLPI on PGHS-2 indicated that this should also be reflected in the production of prostaglandins. Because $\mathrm{PGE}_{2}$ is the specific prostaglandin involved in the regulation of MMP by monocytes/macrophages $(8,10)$, the levels of this arachidonic acid metabolite were determined in the supernatants from monocyte cultures to which SLPI had been added. In agreement with the PGHS-2 results, SLPI caused a dosedependent reduction in the levels of $\mathrm{PGE}_{2}$ induced by LPS with significant inhibition occurring at $1-10 \mu \mathrm{g} / \mathrm{ml}$ of SLPI (Fig. 3). The suppression of $\mathrm{PGE}_{2}$ by SLPI was related to inhibition of synthesis of PGHS-2 rather than an effect on PGHS-2 activity since the addition of SLPI after the induction of PGHS-2 failed to block subsequent $\mathrm{PGE}_{2}$ production (data not shown).

SLPI inhibition of the production of MMPs by monocytes. The ability of SLPI to suppress PGHS-2 and PGE 2 suggested that it should also inhibit the production of MMPs by monocytes. We examined the influence of SLPI on the production of gelatinase B (MMP-9) and interstitial collagenase (MMP-1), two major MMPs produced by monocytes. As shown by zymography (Fig. $4 A$ ), LPS caused a fourfold enhancement in the levels of MMP-9 over that detected in control monocyte cultures (Fig. 4 B). The induction of MMP-9 by LPS was signif-

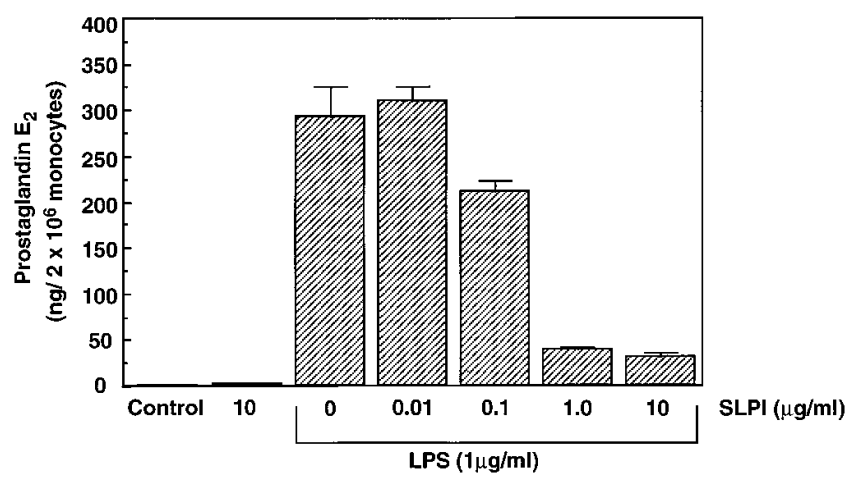

Figure 3. Inhibition of monocyte $\mathrm{PGE}_{2}$ production by SLPI. Purified human peripheral blood monocytes, $2 \times 10^{6} / 0.5 \mathrm{ml}$ of DME, were cultured in 24-well plates in the absence or presence of the indicated concentrations of SLPI for $30 \mathrm{~min}$. Then LPS $(1 \mu \mathrm{g} / \mathrm{ml})$ was added to some of the cultures, and the media harvested $24 \mathrm{~h}$ later was assayed for $\mathrm{PGE}_{2}$ by radioimmunoassay. The data represent the mean $\pm \mathrm{SD}$ of duplicate samples. 

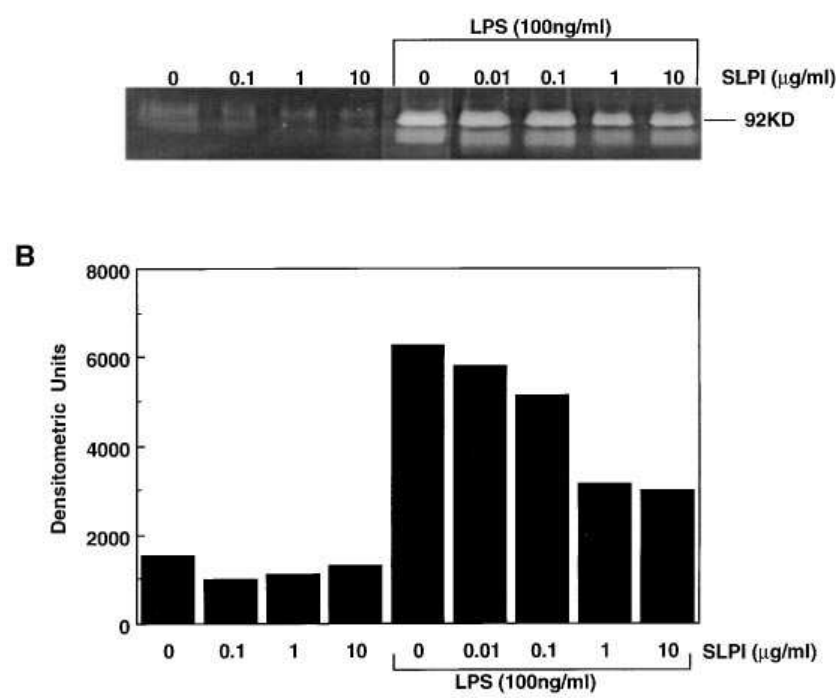

Figure 4. SLPI suppression of monocyte MMP-9 production. Purified monocytes, $2 \times 10^{6} / 0.5 \mathrm{ml}$ of DME, were cultured in 24-well plates in the presence or absence of the indicated concentrations of SLPI for $30 \mathrm{~min}$ before the addition of LPS $(100 \mathrm{ng} / \mathrm{ml})$. The culture supernatants harvested at $48 \mathrm{~h}$ were tested for MMP-9 by zymography $(A)$, and the data were compared by densitometric analysis $(B)$.

icantly inhibited by SLPI, as is particularly evident at concentrations of 1 and $10 \mu \mathrm{g} / \mathrm{ml}$, which resulted in a reduction of $\sim 50 \%$ as determined by densitometric analysis (Fig. $4 B$ ). We next examined the effect of SLPI on MMP-1 at the mRNA and protein level. As shown in Fig. $5 A$, mRNA for MMP-1 is absent in control cells while LPS treatment results in the induc-

A
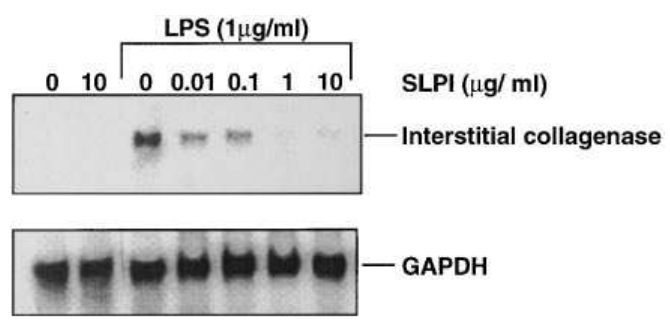

B

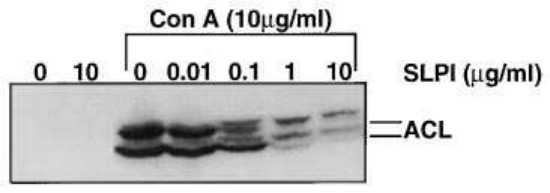

Figure 5. Inhibition of monocyte MMP-1 production by SLPI. Purified monocytes, $20 \times 10^{6} / 4 \mathrm{ml}$ of DME, were cultured either in suspension for mRNA determination by Northern blot $(A)$ or adherent for protein measurement by Western analysis $(B)$. The cells were cultured in the presence or absence of SLPI for 30 min before the addition of LPS or Con A. The cultures were harvested at $18 \mathrm{~h}$ for mRNA and at $48 \mathrm{~h}$ for Western analysis (the active forms of collagenase $[A C L]$ were $\sim 45$ and $43 \mathrm{kD}$ ). tion of mRNA for this enzyme. In this experiment the addition of SLPI at a concentration as low as $0.01 \mu \mathrm{g} / \mathrm{ml}$ resulted in detectable inhibition while at concentrations of 1 and $10 \mu \mathrm{g} / \mathrm{ml}$ caused a dramatic suppression of MMP-1 mRNA. When the protein levels of MMP-1 were examined by Western analysis (Fig. $5 \mathrm{~B}$ ), inhibition of LPS-induced MMP-1 was clearly detected with $0.1 \mu \mathrm{g} / \mathrm{ml}$ of SLPI while at $10 \mu \mathrm{g} / \mathrm{ml}$ the production of MMP-1 protein was almost completely blocked. The 45 and $43 \mathrm{kD}$ active forms of collagenase (ACL) are evident with Con A alone and Con A plus $0.01 \mu \mathrm{g} / \mathrm{ml}$ of SLPI. In this experiment, it was noted that the media from Con A-treated monocytes that received the higher concentrations of SLPI ( 0.1 to 10 $\mu \mathrm{g} / \mathrm{ml})$ contained altered forms of active MMP-1. The ability of SLPI to inhibit MMP production was lost if it was added 30 min after LPS or Con A (data not shown), which correlated with the failure to inhibit the requisite induction of PGHS-2 (Fig. 2).

Reversal of SLPI inhibitory effects on monocyte function by $B t_{2} C A M P$ and $P G E_{2}$. In addition to MMP production by monocytes being dependent on $\mathrm{PGE}_{2}$ and cAMP, we and others have shown that PGHS-2 is also regulated by these agents. To determine if the mechanism by which SLPI blocked PGHS-2 and MMP production was related to suppression of $\mathrm{PGE}_{2}$, either $\mathrm{PGE}_{2}$ or $\mathrm{Bt}_{2} \mathrm{cAMP}$ were added to SLPI treated monocytes. As shown in Fig. 6, the inhibition of PGHS-2 mRNA in Con A-activated monocytes by SLPI was reversed by the addition of $\mathrm{PGE}_{2}$ or $\mathrm{Bt}_{2} \mathrm{cAMP}$. The addition of $\mathrm{PGE}_{2}$ or $\mathrm{Bt}_{2} \mathrm{cAMP}$ to unstimulated monocytes did not induce PGHS-2 mRNA or protein (data not shown). Similarly, as shown for MMP-1 in Fig. 7, MMP production was also restored in SLPItreated monocytes by $\mathrm{PGE}_{2}$ or $\mathrm{Bt}_{2} \mathrm{cAMP}$. Thus SLPI appears, at least in part, to exert its inhibitory effects on MMP production by interfering with the induction of PGHS-2 and the generation of $\mathrm{PGE}_{2}$.

Comparison of SLPI with SLPI muteins and other serine proteases on monocyte prostaglandin $H$ synthase-2 and MMP production. SLPI has been demonstrated to directly inhibit the enzymatic activity of several serine proteases (such as

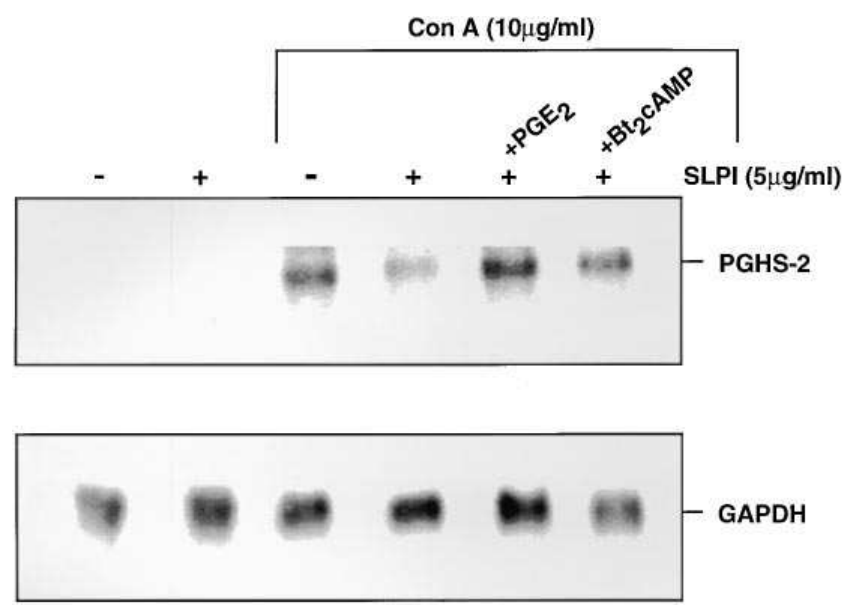

Figure 6. Reversal of SLPI inhibition of monocyte PGHS-2 by $\mathrm{PGE}_{2}$ or $\mathrm{Bt}_{2} \mathrm{cAMP}$. Purified monocytes, $20 \times 10^{6} / 4 \mathrm{ml}$ of DME, were cultured in suspension. SLPI was added for $30 \mathrm{~min}$ before the addition of Con $\mathrm{A}$ and $\mathrm{PGE}_{2}\left(10^{-7} \mathrm{M}\right)$ or $\mathrm{Bt}_{2} \mathrm{cAMP}\left(5 \times 10^{-5} \mathrm{M}\right)$. The cultures were harvested at $18 \mathrm{~h}$ and the mRNA analyzed by Northern blot with the indicated probes. 


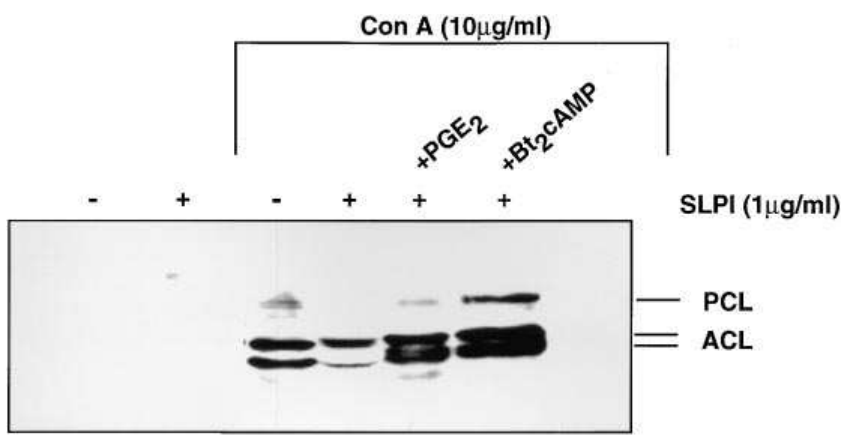

Figure 7. Reversal of SLPI inhibition of monocyte MMP-1 by $\mathrm{PGE}_{2}$ or $\mathrm{Bt}_{2} \mathrm{cAMP}$. SLPI was added to adherent monocyte cultures, $20 \times$ $10^{6} / 4 \mathrm{ml} 30 \mathrm{~min}$ before the addition of Con $\mathrm{A}$ and $\mathrm{PGE}_{2}\left(10^{-7} \mathrm{M}\right)$ or $\mathrm{Bt}_{2} \mathrm{cAMP}\left(5 \times 10^{-5} \mathrm{M}\right)$. The cultures were harvested at $48 \mathrm{~h}$ and the media levels of MMP-1 determined by Western analysis. The $57-\mathrm{kD}$ procollagenase form $(P C L)$ and the $45-$ and $43-\mathrm{kD}$ active collagenase forms $(A C L)$ are indicated.

elastase and cathepsin $\mathrm{G}$ which are both expressed in monocytes) (1-4). The possibility that SLPI may be blocking the induction of PGHS-2 and MMPs through its inhibition of cellular proteases that may mediate signaling was examined by exposing monocytes to SLPI muteins or other serine protease inhibitors. Although the substitution of glycine, phenylalanine, arginine, lysine, or valine by site-directed mutagenesis for leucine 72 in the $\mathrm{COOH}$ terminus of SLPI significantly decreases the antiprotease activity of these muteins (5), they still retained the ability to inhibit PGHS-2 (Fig. $8 A$ ) and MMP (Fig. $8 B$ ) induction to the same degree as SLPI. These results suggest that SLPI mediates its inhibitory effect through an antiprotease independent mechanism. Further support for this conclusion comes from comparison of SLPI with other serine protease inhibitors. As shown in Fig. 9, while SLPI caused a dose-dependent inhibition of MMP, the serine protease inhibitors AEBSF [4-(2-aminoethyl)-benzenesulfonylfluoride hydrochloride] (an aqueous soluble inhibitor, which has similar inhibitory characteristics as PMSF); soybean trypsin inhibitor (STI), or $\alpha$-PI ( $\alpha$-protease inhibitor; an elastase inhibitor) failed to inhibit the induction of MMP-1 (Fig. $9 A$ ) or MMP-9 (Fig. 9 B). However, the highest concentration of AEBSF tested did inhibit the conversion of the latent forms of MMP-1 to its active forms (Fig. 9 $A$ ). Thus, the inhibition of monocyte PGHS-2 and MMPs by SLPI is through a mechanism primarily unrelated to its effect on serine proteases.

Effect of SLPI on cytokine production by monocytes. One possible mechanism by which SLPI may regulate the induction of PGHS-2 and MMP in monocytes is through its ef-
A

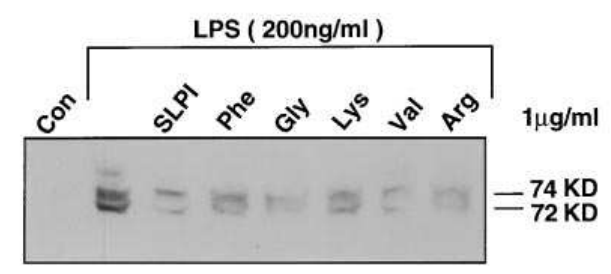

B

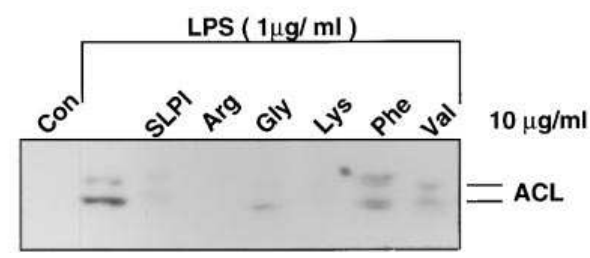

Figure 8. Comparison of SLPI with SLPI muteins on the induction of monocyte PGHS-2 and MMP-1. SLPI or SLPI muteins in which leucine 72 in the $\mathrm{COOH}$ terminus of SLPI had been replaced with phenylalanine, glycine, lysine, valine, or arginine by site directed mutagenesis were added to adherent monocyte cultures $\left(20 \times 10^{6} / 4 \mathrm{ml}\right.$ of DME) $30 \mathrm{~min}$ before the addition of LPS. (A) For determination of PGHS-2 levels the cultures were harvested $18 \mathrm{~h}$ after the addition of LPS and equal amounts of membrane protein $(100 \mu \mathrm{g} / \mathrm{ml})$ were separated on $8 \%$ discontinuous Tris-glycine gels and subjected to Western blot analysis using affinity purified PGHS-2 antisera. $(B)$ MMP-1 levels were determined in culture media harvested $48 \mathrm{~h}$ after stimulation with LPS by Western analysis. The active forms of MMP-1 $(A C L)$ are indicated.

fect on cytokine synthesis by these cells. Therefore the effect of SLPI on the levels of TNF- $\alpha$, a proinflammatory cytokine, and IL-10, which has been shown to suppress PGHS-2 and MMPs (14) was determined. As shown in Fig. 10, SLPI had no significant effect on the induction by LPS of TNF- $\alpha$ (Fig. $10 A$ ) and a slight inhibitory effect on IL-10 (Fig. $10 \mathrm{~B}$ ). SLPI also had no effect on IL-6 production (data not shown). These findings indicate that SLPI does not appear to mediate its effects by altering cytokines that might regulate PGHS-2 and MMP production.

\section{Discussion}

SLPI, believed to be an important inhibitor of neutrophil elastase and cathepsin G (3), is found in the fluids lining mu-
A

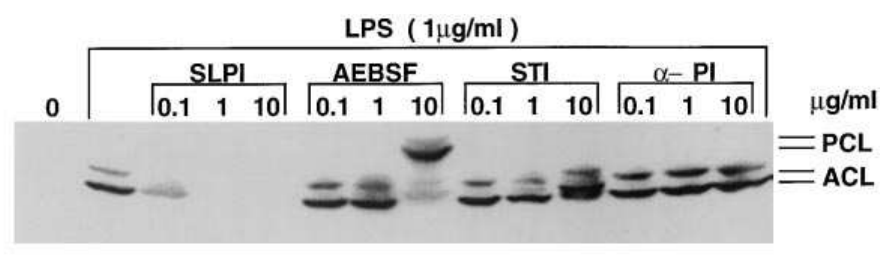

B

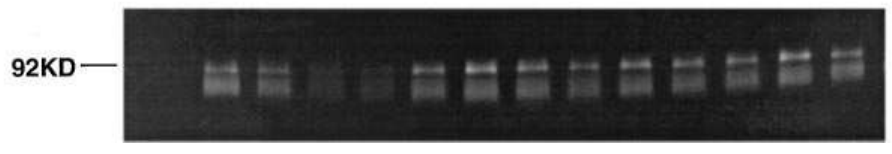

Figure 9. Comparison of the effect of SLPI with other serine protease inhibitors on monocyte MMP production. SLPI, AEBSF, soybean trypsin inhibitor, or $\alpha_{1}$-protease inhibitor were added at the indicated concentrations to adherent monocytes $\left(20 \times 10^{6} / 4 \mathrm{ml}\right.$ of DME) for $30 \mathrm{~min}$ before the addition of LPS. The cultures were harvested at $48 \mathrm{~h}$ and the media assayed for MMP-1 by Western analysis $(A)$ and MMP9 by zymography $(B)$. In panel $A$ the proforms of collagenase $(P C L)$ and active forms of collagenase $(A C L)$ are indicated. 


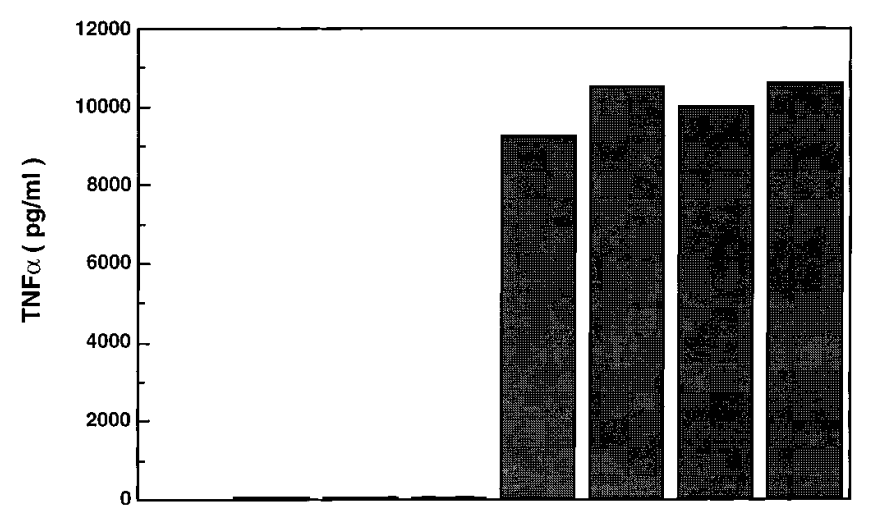

B

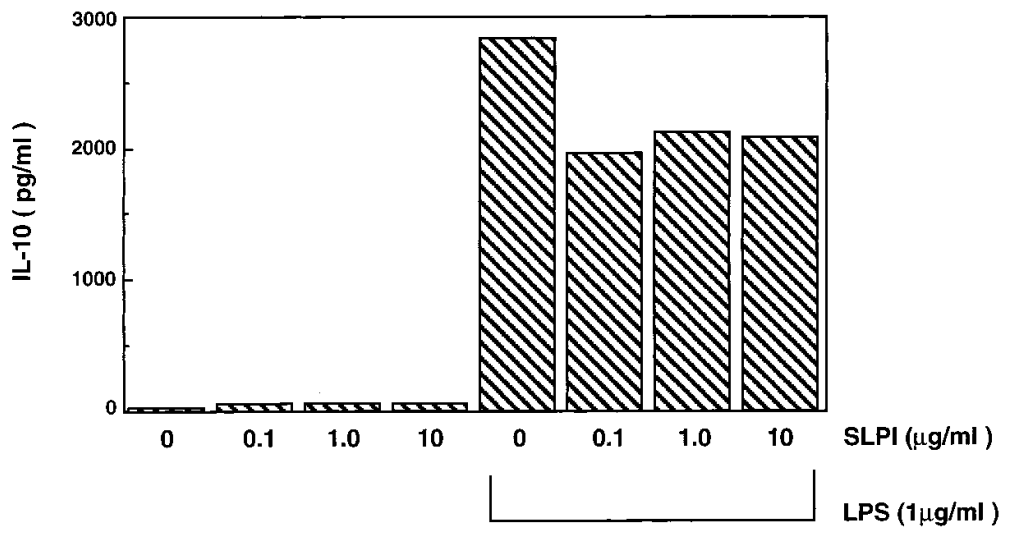

Figure 10. Effect of SLPI on TNF- $\alpha$ and IL-10 production by monocytes. Purified monocytes were cultured in 24-well plates at $2 \times 10^{6}$ cells $/ 0.5 \mathrm{ml}$ of DME. SLPI was added $30 \mathrm{~min}$ before LPS and the culture supernatants harvested $24 \mathrm{~h}$ later and the levels of TNF- $\alpha$ and IL-10 determined by ELISA. The data represent the mean of duplicate samples.

cosal surfaces in the oral cavity and upper respiratory tract, suggesting that it may play an important role in host defense against proteases incited by a variety of pathogens. Indeed, SLPI has been indicated as a protective agent against damage of the human respiratory epithelial surface by neutrophil elastase (28). Additionally, its presence in saliva suggests that it may also play an important role in regulating inflammation in the oral cavity where exposure to numerous bacteria and their products may induce the synthesis of destructive enzymes.

While the function of SLPI has been implicated in the regulation of inflammation by direct inhibition of proteases, the findings presented here demonstrated that it may also have a significant role in suppressing the destruction of connective tissue by blocking the signal transduction pathway leading to the production of MMPs by monocytes. The ability of SLPI to block MMP production appears to be related to its inhibition of $\mathrm{PGE}_{2}$ due to the suppression of PGHS-2. This is supported by the restoration of PGHS-2 and MMP production by the addition of either $\mathrm{PGE}_{2}$ or $\mathrm{Bt}_{2} \mathrm{cAMP}$. The precise mechanism by which SLPI inhibits PGHS-2 and the subsequent production of $\mathrm{PGE}_{2}$ is unclear. However, it does not appear to be due to the inhibition of phospholipase activity, an earlier event in this signal transduction cascade, since the LPS-induced release of arachidonic acid was unaffected by SLPI (data not shown). Additionally, SLPI does not function as a general metabolic inhibitor since the induction of IL-2 receptor expression in monocytes by LPS is unaffected by SLPI (6).
SLPI has recently been shown to inhibit HIV-1 infection of monocytes through mechanisms that may be independent of its antiprotease activity (McNeely, T.B., D.C. Shugars, M. Rosendahl, C. Tucker, S.P. Eisenberg, and S.M. Wahl, manuscript in preparation). Evidence that the suppression of the induction of monocyte MMP by SLPI is unrelated to its protease inhibitory properties is based on the ability of SLPI muteins, which have significantly reduced antiprotease activity, to also inhibit this pathway and the failure of other serine protease inhibitors to block the induction of MMPs. Tissue inhibitor of metalloproteinases-1 (TIMP-1) and -2 (TIMP-2) are other examples of protease inhibitors that modulate cellular responses through mechanisms other than the inhibition of proteases. TIMP-1 and TIMP-2 have been shown to have potent growthpromoting activity for a wide range of cells $(29,30)$. Moreover, TIMP-2 has been shown to exert its growth-promoting effects through the modulation of cAMP (31). Thus, it is possible that some protease inhibitors may in fact exert potent regulatory effects that are potentially more biologically profound than their ability to inhibit proteases.

The precise point at which SLPI interrupts the signal transduction pathway leading to the induction of PGHS-2 and MMPs is not clear. However, it does not appear to be due to modulation of cytokine production by monocytes. SLPI did not effect TNF- $\alpha$ production, which is known to activate many monocyte functions. IL-10 is a cytokine produced by monocytes that has been shown to inhibit the induction of PGHS-2 
and MMPs by these cells (14). However, SLPI did not enhance IL-10 production but rather caused a slight decrease in the levels of this cytokine.

The concentrations of SLPI $(0.1-10 \mu \mathrm{g} / \mathrm{ml})$ that exhibited inhibitory activity on the monocyte functions described here were well within the physiological concentrations found in various body fluids. Examples of SLPI amounts in biological fluids include: saliva (4-24 $\mu \mathrm{g} / \mathrm{ml})(6)$ and bronchoalveolar lavage fluid $(0.14 \pm 0.06 \mu \mathrm{g} / \mathrm{ml})$ or bronchial lavage fluid $(2.08 \pm 1.16$ $\mu \mathrm{g} / \mathrm{ml}$ ) (32). In addition to the production of SLPI by epithelial cells lining mucosal surfaces, this inhibitor is also produced by human articular cartilage chondrocytes and fibrochondrocytes (33) and thus may function as an important regulator of MMPs at these sites.

MMPs are believed to play a crucial role in the destruction of connective tissue in chronic inflammatory lesions, thus it is important to identify natural inhibitors that suppress the production of these enzymes. SLPI is clearly a potent inhibitor of the signal transduction pathway in monocytes leading to the production of MMPs. Understanding the manner in which SLPI production is regulated and the precise mechanism by which it suppresses MMP synthesis may provide important approaches in the regulation of connective tissue destruction.

\section{Acknowledgments}

The authors are grateful to Amgen Inc., Boulder, $\mathrm{CO}$, for generously supplying recombinant SLPI and SLPI muteins, to Dr. William Stetler-Stevenson, National Cancer Institute, National Institutes of Health (NIH) for antibody 125 against MMP-1 and Dr. Henning Birkedal-Hansen, National Institute of Dental Research (NIDR), NIH for antibody 647 against MMP-1.

This work was performed while Yahong Zhang held a National Research Council-NIDR/NIH Research Associateship.

\section{References}

1. Seemüller, U., M. Arnhold, H. Fritz, K. Wiedenmann, W. Machleidt, R. Heinzel, H. Appelhans, H.-G. Gassen, and F. Lottspeich. 1986. The acid-stable proteinase inhibitor of human mucous secretions (HUSI-I. antileukoprotease). FEBS Lett. 199:43-48.

2. Ohlsson, K., M. Rosengren, G. Stetler, M. Brewer, K.K. Hale, and R.C. Thompson. 1986. Structure, genomic organization and tissue distribution of human secretory leukocyte-protease inhibitor (SLPI): a potent inhibitor of neutrophil elastase. In Pulmonary Emphysema and Proteolysis. J.C. Taylor and C. Mittman, editors. Academic Press II; Orlando, FL. 307-322.

3. Thompson, R.C., and K. Ohlsson. 1986. Isolation, properties, and complete amino acid sequence of human secretory leukocyte protease inhibitor, a potent inhibitor of leukocyte elastase. Proc. Natl. Acad. Sci. USA. 83:66926696.

4. Stetler, G., M.T. Brewer, and R.C. Thompson. 1986. Isolation and sequence of a human gene encoding a potent inhibitor of leukocyte proteases. Nucleic Acids Res. 14:7883-7896.

5. Eisenberg, S.P., K.K. Hale, P. Heimdal, and R.C. Thompson. 1990. Location of the protease-inhibitory region of secretory leukocyte protease inhibitor. J. Biol. Chem. 265:7976-7981.

6. McNeely, T.B., M. Dealy, D.J. Dripps, J.M. Orenstein, S.P. Eisenberg, and S.M. Wahl. 1995. Secretory leukocyte protease inhibitor: a human saliva protein exhibiting anti-human immunodeficiency virus 1 activity in vitro. $J$. Clin. Invest. 96:456-464.

7. Birkedal-Hansen, H., W.G.I. Moore, M.K. Bodden, L.J. Windsor, B. Birkedal-Hansen, A. DeCarlo, and J.A. Engler. 1993. Matrix metalloproteinases: a review. Crit. Rev. Oral Biol. Med. 4:197-250.

8. Wahl, L.M., C.E. Olsen, A.L. Sandberg, and S.E. Mergenhagen. 1977. Prostaglandin regulation of macrophage collagenase production. Proc. Natl. Acad. Sci. USA. 74:4955-4958.

9. McCarthy, J.B., S.M. Wahl, J.C. Rees, C.E. Olsen, A.L. Sandberg, and L.M. Wahl. 1980. Regulation of macrophage collagenase production by $3^{\prime}-5^{\prime}$ cyclic adenosine monophosphate. J. Immunol. 124:2405-2409.

10. Wahl, L.M., and L.L. Lampel. 1987. Regulation of human peripheral blood monocyte collagenase by prostaglandins and anti-inflammatory drugs. Cell. Immunol. 105:411-422.

11. Corcoran, M.L., W.G. Stetler-Stevenson, P.D. Brown, and L.M. Wahl. 1992. Interleukin 4 inhibition of prostaglandin $E_{2}$ synthesis blocks interstitial collagenase and $92-\mathrm{kDa}$ type IV collagenase/gelatinase production by human monocytes. J. Biol. Chem. 267:515-519.

12. Shapiro, S.D., D.K. Kobayashi, A.P. Pentland, and H.G. Welgus. 1993. Induction of macrophage metalloproteinase by extracellular matrix. Evidence for enzyme-and substrate-specific responses involving prostaglandin-dependent mechanisms. J. Biol. Chem. 268:8170-8175.

13. Corcoran, M.L., W.G. Stetler-Stevenson, D.L. DeWitt, and L.M. Wahl. 1994. Effect of cholera toxin and pertussis toxin on prostaglandin $H$ synthase-2, prostaglandin $\mathrm{E}_{2}$, and matrix metalloproteinase production by human monocytes. Arch. Biochem. Biophys. 310:481-488.

14. Mertz, P.M., D.L. DeWitt, W.G. Stetler-Stevenson, and L.M. Wahl. 1994. Interleukin 10 suppression of monocyte prostaglandin $H$ synthase-2: mechanism of inhibition of prostaglandin dependent matrix metalloproteinase production. J. Biol. Chem. 269:21322-21329.

15. Busiek, D.F., V. Baragi, L.C. Nehring, W.C. Parks, and H.G. Welgus. 1995. Matrilysin expression by human mononuclear phagocytes and its regulation by cytokines and hormones. J. Immunol. 154:6484-6491.

16. DeWitt, D., and W.L. Smith. 1995. Yes, but do they still get headaches? Cell. 83:345-348.

17. O'Sullivan, M.G., F.H. Chilton, E.M. Huggins, Jr., and C.E. McCall. 1992. Lipopolysaccharide priming of alveolar macrophages for enhanced synthesis of prostanoids involves induction of a novel prostaglandin $\mathrm{H}$ synthase. $J$. Biol. Chem. 267:14547-14550.

18. Lee, S.H., E. Soyoola, P. Chanmugam, S. Hart, W. Sun, H. Zhong, S. Liou, D. Simmons, and D. Hwang. 1992. Selective expression of mitogen-inducible cyclooxygenase in macrophages stimulated with lipopolysaccharide. J. Biol. Chem. 267:25934-25938.

19. Hla, T., and K. Neilson. 1992. Human cyclooxygenase-2 cDNA. Proc. Natl. Acad. Sci. USA. 89:7384-7388.

20. Wahl, L.M., I.M. Katona, R.L. Wilder, C.C. Winter, B. Haraoui, I. Sher, and S.M. Wahl. 1984. Isolation of human mononuclear cell subsets by counterflow centrifugal elutriation (CCE). II. Functional properties of B-lymphocyte-, T-lymphocyte and monocyte-enriched fractions. Cell. Immunol. 85:373-383.

21. Wahl, L.M., and P. Smith. 1991. Isolation of monocyte/macrophage populations. In Current Protocols in Immunology. J.E. Coligan, A.M. Kruisbeek, D.H. Margulies, E.M. Shevach, and W. Strober, editors. John Wiley \& Sons, Inc., New York. 7.6.1-7.6.6.

22. Wahl, S.M., N. McCartney-Francis, D.A. Hunt, P.D. Smith, L.M. Wahl, and I.M. Katona. 1987. Monocyte interleukin 2 receptor gene expression and interleukin 2 augmentation of microbicidal activity. J. Immunol. 139:1342-1347.

23. Chomczynski, P., and N. Sacchi. 1987. Single-step method of RNA isolation by acid guanidinium thiocyanate-phenol-chloroform extraction. Anal. Biochem. 362:156-159.

24. Meade, E.A., W.L. Smith, and D.L. DeWitt. 1993. Expression of the murine prostaglandin (PGH) synthase-1 and PGH synthase-2 isozymes in cos-1 cells. J. Lipid Mediat. 6:119-129.

25. Whitham, S.E., G. Murphy, P. Angel, H.J. Rahmsdorf, B.J. Smith, A. Lyons, T.J. Harris, J.J. Reynolds, P. Herrlich, and A.J. Docherty. 1986. Biochem. J. 240:913-916.

26. Wahl, L.M. 1981. Production and quantitation of prostaglandins. In Manual of Macrophage Methodology. H.B. Herscowitz, H.T. Holden, J.A. Bellanti, and A. Ghaffar, editors. Marcel Dekker, Inc., New York and Basel. 423429 .

27. Kujubu, D.A., B.S. Fletcher, B.C. Varnum, R.W. Lim, and H.R. Herschman. 1991. TIS10, a phorbol ester tumor promoter-inducible mRNA from Swiss 3 T3 cells, encodes a novel prostaglandin synthase/cyclooxygenase homologue. J. Biol. Chem. 266:12866-12872.

28. Vogelmeier, C., R.C. Hubbard, G.A. Fells, H.-P. Schnebli, R.C. Thompson, H. Fritz, and R.G. Crystal. 1991. Anti-neutrophil elastase defense of the normal human respiratory epithelial surface provided by the secretory leukoprotease inhibitor. J. Clin. Invest. 87:482-488.

29. Hayakawa, T., K. Yamashita, K. Tanzawa, E. Uchijima, and K. Iwata. 1992. Growth-promoting activity of tissue inhibitor of metalloproteinases-1 (TIMP-1) for a wide range of cells. A possible new growth factor in serum. FEBS Lett. 298:29-32.

30. Hayakawa, T., K. Yamashita, E. Ohuchi, and A. Shinagawa. 1994. Cell growth-promoting activity of tissue inhibitor of metalloproteinases-2 (TIMP-2). J. Cell Sci. 107:2373-2379.

31. Corcoran, M.L., and W.G. Stetler-Stevenson. 1995. Tissue inhibitor of metalloproteinase-2 stimulates fibroblast proliferation via a cAMP-dependent mechanism. J. Biol. Chem. 270:13453-13459.

32. Kouchi, I., S. Yasuoka, Y. Ueda, and T. Ogura. 1993. Analysis of secretory leukocyte protease inhibitor (SLPI) in bronchial secretions from patients with hypersecretory respiratory diseases. Tokushima J. Exp. Med. 40:95-107.

33. Jacoby, A.S., J. Melrose, B.G. Robinson, V.J. Hyland, and P. Ghosh. 1993. Secretory leucocyte proteinase inhibitor is produced by human articular cartilage chondrocytes and intervertebral disc fibrochondrocytes. Eur. J. Biochem. 218:951-957. 